\title{
Flight Test Results of an Axisymmetric Channeled Center-body Supersonic Inlet at Off-Design Conditions
}

\author{
Clinton W. St. John ${ }^{1}$ and Michael A. Frederick ${ }^{2}$ \\ NASA Dryden Flight Research Center, Edwards, California, 93523
}

\begin{abstract}
Flight-testing of a channeled center-body axisymmetric supersonic inlet design concept was conducted at the National Aeronautics and Space Administration (NASA) Dryden Flight Research Center in collaboration with the NASA Glenn Research Center (Cleveland, Ohio) and TechLand Research, Inc. (North Olmsted, Ohio). This testing utilized the Propulsion Flight Test Fixture, flown on the NASA F-15B research test bed airplane (NASA tail number 836) at local experiment Mach numbers up to 1.50. The translating channeled center-body inlet was designed by TechLand Research, Inc. (U.S. Patent No. 6,276,632 B1) to allow for a novel method of off-design flow matching, with original test planning conducted under a NASA Small Business Innovative Research study. Data were collected in flight at various off-design Mach numbers for fixed-geometry representations of both the channeled center-body design and an equivalent area smooth center-body design for direct comparison of total pressure recovery and limited distortion measurements.
\end{abstract}

$\begin{array}{ll} & \\ \mathrm{AOA} & =\text { Nomenclature } \\ A_{\text {in }} & =\text { inlet capture area } \\ A_{\text {th }} & =\text { nozzle throat area } \\ \mathrm{C} & =\text { channeled center-body } \\ \mathrm{CCIE} & =\text { Channeled Center-body Inlet Experiment } \\ \mathrm{M} & =\text { Mach } \\ M_{\text {Inlet }} & =\text { Mach number of the airflow ahead of the inlet } \\ \dot{m}_{\text {Inlet }} & =\text { mass flow through the inlet } \\ \dot{m}_{\text {Max }} & =\text { theoretical maximum mass flow through the inlet } \\ \mathrm{NASA} & =\text { National Aeronautics and Space Administration } \\ \mathrm{PFTF} & =\text { Propulsion Flight Test Fixture } \\ P_{\text {Avg }} & =\text { average of the measured pressures from all three rakes } \\ P_{\text {Max }} & =\text { maximum measured pressure from all three rakes } \\ P_{\text {Min }} & =\text { minimum measured pressure from all three rakes } \\ P_{\text {Noz }} & =\text { average of the measured nozzle static pressures } \\ P_{0_{\text {Inlet }}} & =\text { total pressure of the airflow ahead of the inlet } \\ \text { psia } & =\text { pounds force per square inch absolute } \\ \mathrm{R} & =\text { ideal gas constant } \\ \mathrm{RAGE} & =\text { Rake Airflow Gage Experiment } \\ \mathrm{S} & =\text { smooth center-body } \\ \mathrm{TCCB} & =\text { Translating Channeled Center-body } \\ T_{0_{\text {Aircraft }}} & =\text { air flow total temperature ahead of the aircraft } \\ \gamma & =\text { ratio of specific heats }\end{array}$

${ }^{1}$ Aerospace Engineer, Research Engineering Directorate, Aerodynamics Propulsion and Performance Branch, NASA Dryden Flight Research Center, P.O. Box 273, MS 4840B, Edwards, CA, 93523, AIAA Member.

${ }^{2}$ Aerospace Engineer, Research Engineering Directorate, Aerodynamics Propulsion and Performance Branch, NASA Dryden Flight Research Center, P.O. Box 273, MS 2228, Edwards, CA, 93523, AIAA nonmember. 


\section{Introduction}

series of flight tests were conducted using the National Aeronautics and Space Administration (NASA) F-15B (McDonnell Douglas, now The Boeing Company, Chicago, Illinois) research test bed airplane (NASA tail number 836) (Fig. 1) between August 2011 and January 2012 to collect data to perform initial performance evaluations of a translating channeled center-body (TCCB) inlet design concept at off-design conditions and provide data to assist in evaluating computational fluid dynamics (CFD) -predictive capabilities with regard to complex inlet geometries and distortion. The F-15B research test bed airplane is a modified version of the F-15B two-seat high-performance supersonic air-superiority fighter airplane used by the NASA Dryden Flight Research Center (DFRC) to perform aerodynamic and propulsion research in relevant flight environments. All data were obtained for subcritical inlet operation of fixed-geometry hardware designed for the Mach 1.50 off-design configuration of a nominal Mach 2.50 design inlet.

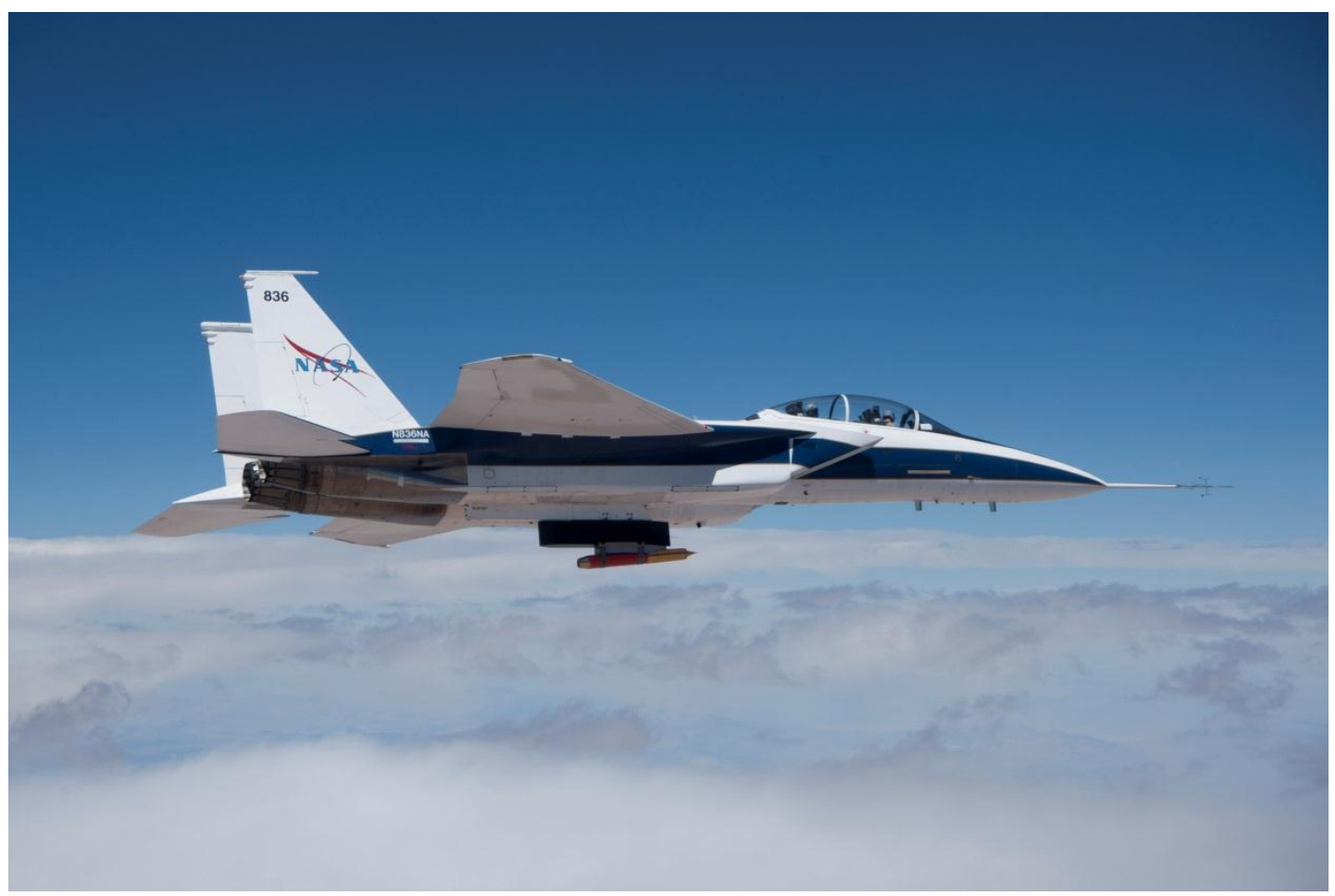

Figure 1. The NASA F-15B, tail number 836, during the first channeled center-body inlet investigation flight.

The TCCB inlet, designed by TechLand Research, Inc. (North Olmsted, Ohio), is a mixed-compression axisymmetric inlet designed for supersonic cruise that allows for greater airflow at off-design conditions via center-body geometry manipulation. This manipulation is accomplished via channels that open in the center-body as the center-body translates, increasing the throat area. Manipulating the geometry of the center-body, instead of only translating the center-body, allows for less supersonic compression internal to the inlet. Typical translating center-body designs require roughly 80 percent internal compression -- below that, more complex methods of geometry manipulation are required to achieve the necessary throat areas for transonic operation. The TCCB inlet designed for this experiment was designed to operate at Mach 2.50, with 53 percent internal compression. ${ }^{1}$ Less internal compression is desired, as it provides for more tolerance to upstream disturbances. ${ }^{1,2}$ Variable diameter center-body designs can also accomplish this, however, the TCCB concept is less mechanically complex than the variable diameter center-body concept (in which the entire center-body grows and shrinks radially). Testing was conducted to gather data at off-design configurations for comparison between the TCCB concept and an equivalent area smooth center-body that would correspond to a variable diameter center-body concept at the same conditions. This report details the experiment setup, the testing conducted, and the data collected during this effort. 


\section{Experiment Description}

The primary objective of the testing was to quantify the flow through the channeled center-body and equivalent area smooth center-body inlets to perform comparisons of performance (primarily pressure recovery, mass capture, and distortion). The secondary objective of the testing was to gather data to enable evaluation of CFD-predictive capabilities.

Flight-testing was conducted in multiple phases. The first phase of testing, known as the Rake Airflow Gage Experiment (RAGE), was conducted to map out the local flow conditions under the aircraft where the inlet would be mounted to collect the data. Figure 2 shows the experiment setup for the local flow investigation flights. The RAGE flow-field survey rake consisted of nine five-hole conical probes mounted in a cruciform configuration. The primary objective of the RAGE was to quantify the local flow field (Mach number, flow angularity, total pressure distortion, and dynamic pressure) at the aerodynamic interface plane of the test inlet and to correlate this flow field to airplane free-stream conditions. Prior to the RAGE flight test, probe calibration data were obtained in a wind tunnel at various combinations of angles of attack and sideslip out to $10 \mathrm{deg}$ at Mach numbers of 1.46, 1.51, and 1.61. Local flow data at the test inlet aerodynamic interface plane were obtained over two flights that occurred in the late summer of 2009. More information on the RAGE experiment can be found in Ref. 3.

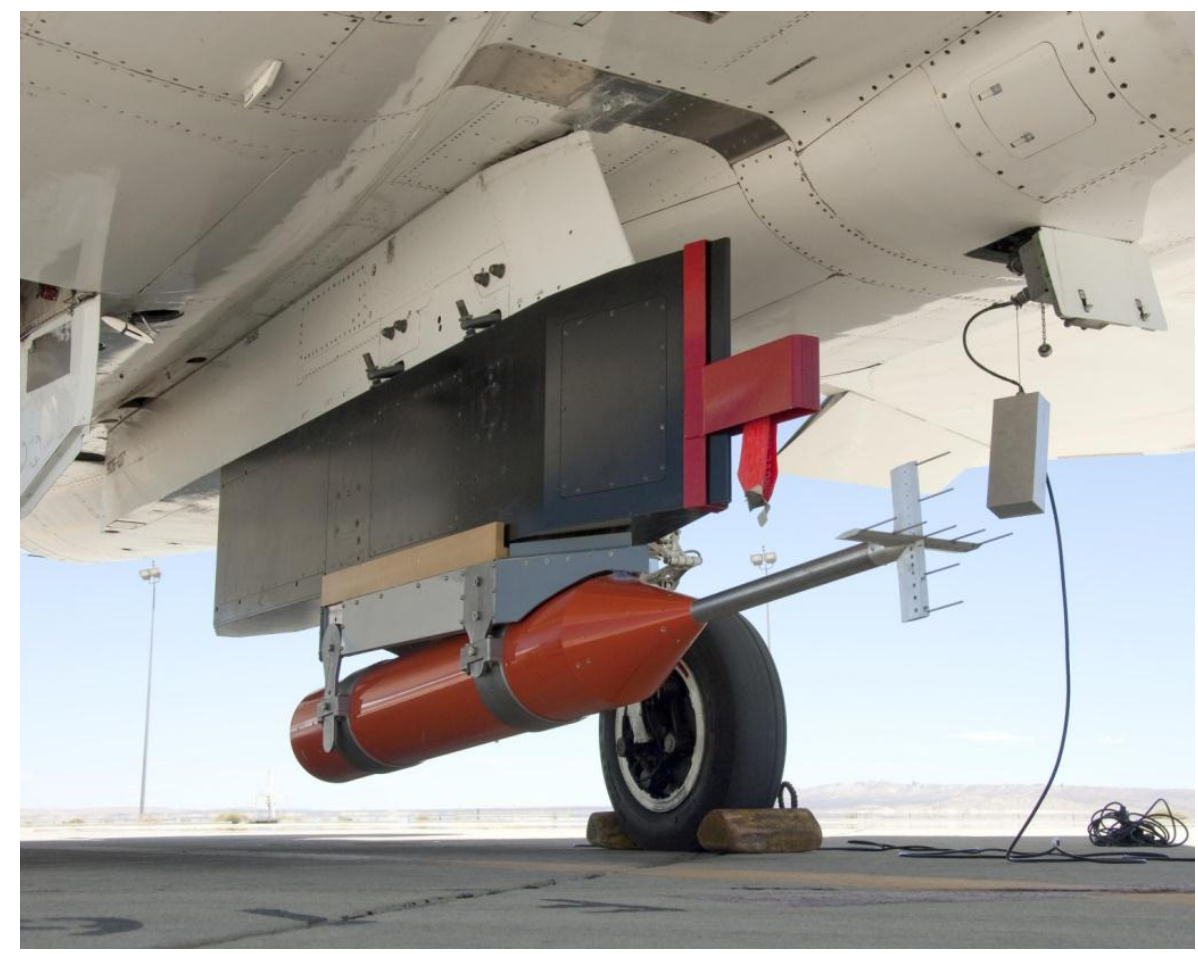

Figure 2. The experiment setup for local flow investigation prior to inlet flight-testing.

The second and third phases of testing collected data on two different fixed-geometry inlet configurations. The second phase collected data for a fixed-geometry channeled center-body inlet configuration with channels fixed in the open position, and the third phase collected data for a smooth center-body configuration with a similar area distribution as the channeled center-body inlet. Figure 3 shows the channeled and smooth center-bodies. Geometry data for the smooth center-body inlet configuration and the channeled center-body inlet configuration can be found in Ref. 4. Data in the form of surface pressures, localized angle of attack (AOA), localized angle of sideslip, Mach number ahead of the inlet, nozzle pressures (for calculating mass flow), and total pressures from a series of rakes used to calculate distortion were collected for both configurations. The channeled center-body had 36 static pressure taps along its surfaces. In addition, a five-port conical probe at the inlet nose, one high-frequency static pressure measurement and 18 total pressure probes were used with this configuration. The smooth center-body was constructed with 18 surface static pressure taps, a five-port conical probe at the inlet nose, one high-frequency static measurement, and 16 total pressure taps. The flow nozzles contained four static pressure taps. The five-hole conical 
probe was installed in both the channeled and smooth center-bodies (forming the tip or apex of the first cone) for measurement of the local flow properties at the tip of the inlet. Prior to flight test, calibration data for the probe were obtained over a Mach number range of 1.20-1.69 and for flow angles out to 6 deg using the NASA Marshall Space Flight Center (MSFC, Huntsville, Alabama) Trisonic Wind Tunnel. From these calibration data, an algorithm was developed for real-time computation of the local flow properties during flight test. While wind tunnel calibration data were only obtained down to Mach 1.20, the algorithm was set up to extrapolate down to Mach 1.05. Table 1 shows the estimated uncertainties in the flow calculations. The high-frequency surface static pressure measurement included in each configuration was an instantaneous measurement (no lag due to pressure tubing runs) utilized in real time, as a data quality check, to examine frequency content in the data and ensure that inlet buzz did not occur. Figure 4 shows the assembled inlet in the channeled configuration. The total pressure rakes used to examine distortion can be seen in the figure.

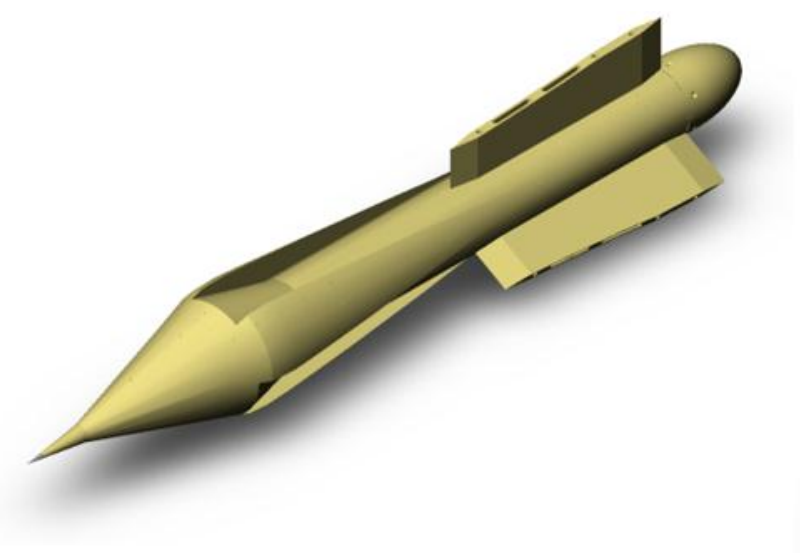

Channeled Center-Body

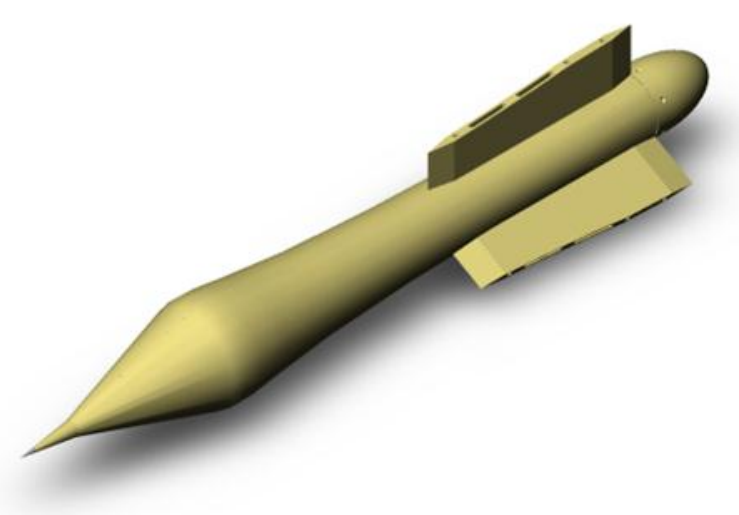

Smooth Center-Body

Figure 3. The channeled and smooth center-body configurations.

Table 1. Experiment conical probe uncertainties.

\begin{tabular}{|c|c|c|c|c|}
\hline & & Mach 1.2 & Mach 1.46 & Mach 1.69 \\
\hline \multirow{2}{*}{$\begin{array}{c}\text { Combined } \\
\text { Uncertainty } \\
\text { Results }\end{array}$} & Angle of Attack (deg) & 0.3 & 0.4 & 0.3 \\
\cline { 2 - 5 } & Sideslip (deg) & 0.4 & 0.6 & 0.4 \\
\cline { 2 - 5 } & Mach Number & 0.01 & 0.01 & 0.01 \\
\hline
\end{tabular}




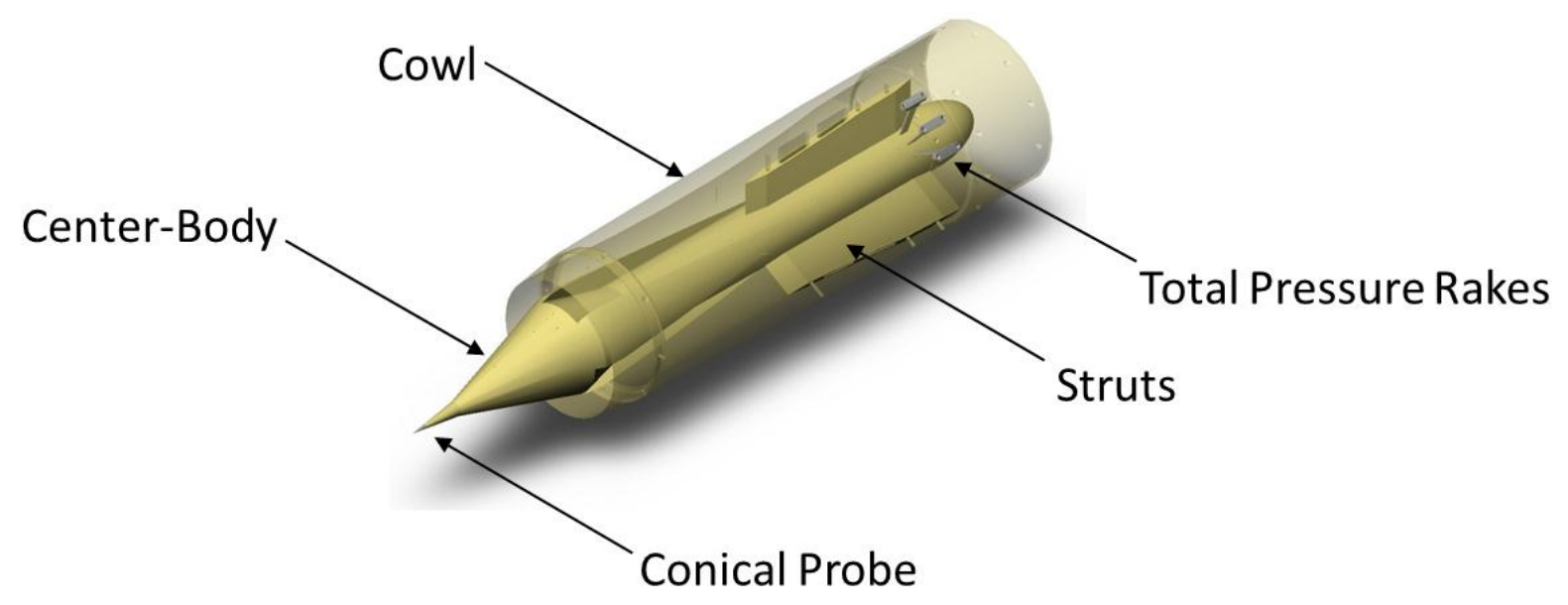

Figure 4. The channeled center-body inlet assembly.

Figure 5 shows the entire experimental setup hanging beneath the F-15B airplane. Key components of the assembly are called out in the figure. The Propulsion Flight Test Fixture (PFTF) structural pylon served as the interface between the experiment and the airplane, through the airplane centerline pylon, and housed the bulk of the instrumentation and signal-conditioning systems. The experiment adapter served as the structural connection between the PFTF structural pylon and the experiment. The inlet was connected to a large open duct, which connected to one of three fixed-geometry nozzles used to set the mass flow through the inlet for the given flight-test condition. The fixed-geometry nozzles were sized such that the area ratio between the nozzle throat (Ath) and the inlet capture area (Ain) were $($ Ath/Ain $)=0.529,0.532$, and 0.548 . Note that the entire inlet experiment assembly was inclined at 5 deg with respect to the aircraft waterline to better align the inlet with the local flow beneath the aircraft at the primary test condition (experiment Mach number of 1.50). This was driven by the local flow angularity measured during the RAGE testing, and the allowable clearance under the aircraft during takeoff and landing. Ideally, the experiment would have been inclined more, as will be evident in the local flow angularity data presented later, but 5 deg was the maximum the experiment could be inclined and still allow the necessary ground clearance. All local flow angularity data presented later for the channeled and smooth center-body configurations are with respect to the inlet as oriented. 


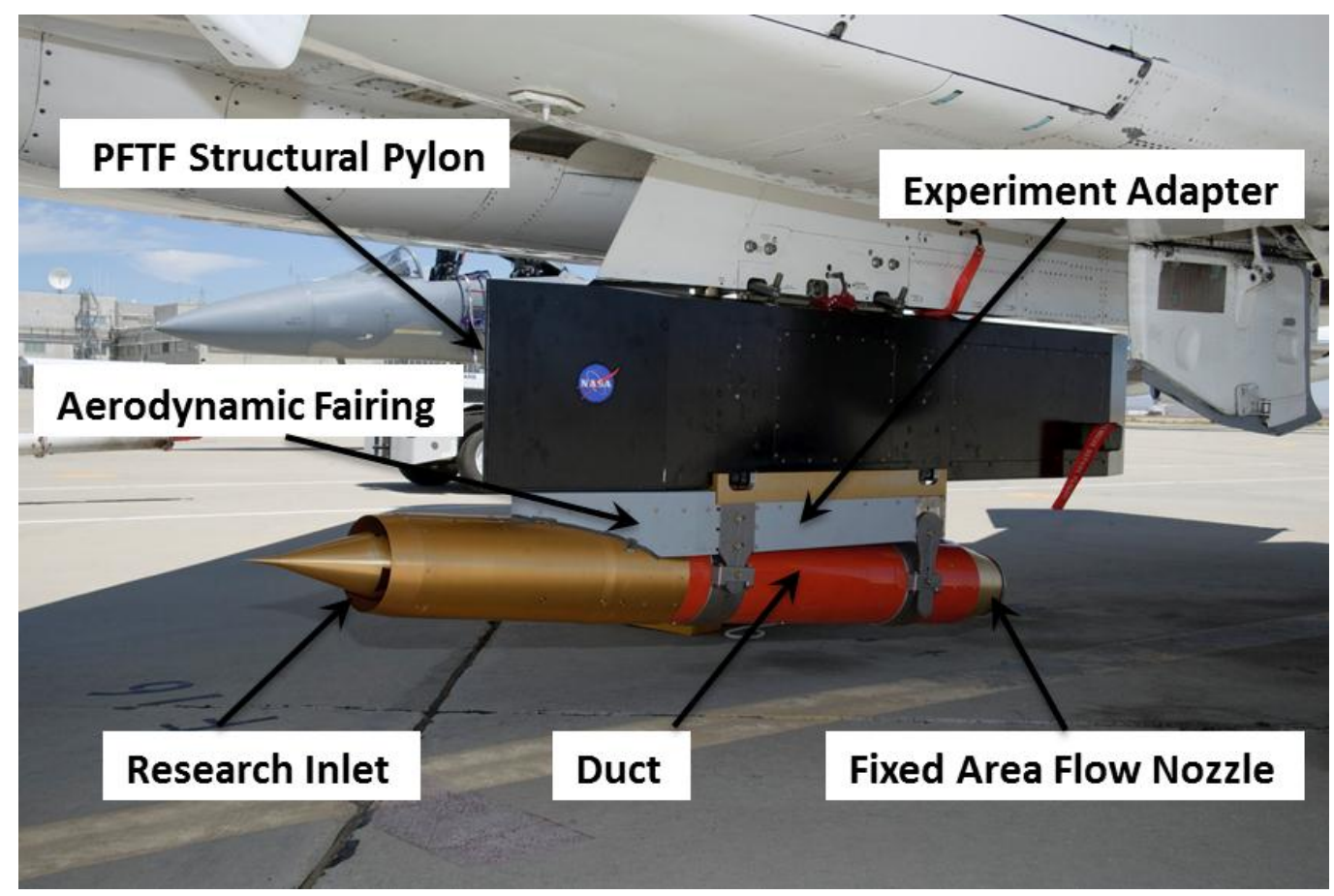

Figure 5. The channeled center-body inlet experiment setup.

\section{Data Collection Flights}

Data were collected for two fixed-geometry inlet configurations and three fixed-geometry nozzles. Table 2 details the flights that were flown. The progression of flights began with the channeled center-body and the smallest fixed-geometry nozzle and then stepped through the fixed-geometry nozzles in order of increasing size. This method was utilized to ensure that the normal shock on the center-body remained in front of the cowl leading edge at the maximum Mach number tested. The normal shock moves aft as the nozzle size increases. By stepping through the nozzles from smallest to largest, the data from each flight could be examined to ensure that the normal shock was always ahead of the cowl leading edge. Following the channeled center-body flights, the experiment was reconfigured with the smooth center-body inlet, and the flights began again, starting, once again, with the smallest nozzle and progressing through the nozzles in order of increasing size. The nominal flight profile for the data collection flights consisted of a normal takeoff and climb to an altitude of $40,000 \mathrm{ft}$, followed by a level acceleration to experiment Mach number of 1.30, a hold for $20 \mathrm{~s}$ on condition after which a continued acceleration to experiment Mach number of 1.50 was conducted, and then $40 \mathrm{~s}$ on condition were held. After the Mach 1.50 test point, a level deceleration back to experiment Mach number of 1.30 was performed and the condition was held for an additional $20 \mathrm{~s}$. Following this hold, the aircraft was decelerated to subsonic flight and a nominal descent, return, and landing were conducted. Control room calls were made to identify on condition and request correction in altitude or Mach number as required over the course of the testing. After the first flight an additional test point was added corresponding to an experiment AOA of 0 deg roughly corresponding to an experiment Mach number of 1.40 on the deceleration portion of the flight between the Mach 1.50 test point and the repeat of the Mach 1.3 test point. The experiment angle under the aircraft was fixed, however, local AOA under the aircraft varies with Mach number. Data were both recorded onboard and telemetered to the ground during the entire flight for each flight. 
Table 2. Inlet data collection flight information.

\begin{tabular}{|c|c|c|c|c|}
\hline Date & Flight & Inlet & $\begin{array}{l}\text { Nozzle } \\
A_{\text {th }} / A_{\text {in }}\end{array}$ & Notes \\
\hline $8 / 17 / 2011$ & 416 & Channeled & 0.529 & $\begin{array}{l}\text { Steady state data collected at experiment Mach } 1.30 \& \\
1.50\end{array}$ \\
\hline $8 / 22 / 2011$ & 417 & Channeled & 0.532 & $\begin{array}{l}\text { Flight aborted due to aircraft left engine compressor } \\
\text { stall }\end{array}$ \\
\hline $8 / 26 / 2011$ & 418 & Channeled & 0.532 & $\begin{array}{l}\text { Flight aborted due to aircraft left engine compressor } \\
\text { stall }\end{array}$ \\
\hline $10 / 18 / 2011$ & 419 & Channeled & 0.532 & $\begin{array}{l}\text { Steady state data collected at experiment Mach } 1.30 \& \\
1.50 \text { as well as } 0 \text { degrees experiment AOA }\end{array}$ \\
\hline $10 / 20 / 2011$ & 420 & Channeled & 0.548 & $\begin{array}{l}\text { Steady state data collected at experiment Mach } 1.30 \& \\
1.50 \text { as well as } 0 \text { degrees experiment AOA }\end{array}$ \\
\hline $11 / 8 / 2011$ & 421 & Smooth & 0.529 & $\begin{array}{l}\text { Steady state data collected at experiment Mach } 1.30 \& \\
1.50 \text { as well as } 0 \text { degrees experiment AOA }\end{array}$ \\
\hline $11 / 14 / 2011$ & 422 & Smooth & 0.532 & $\begin{array}{l}\text { Steady state data collected at experiment Mach } 1.30 \& \\
1.50 \text { as well as } 0 \text { degrees experiment AOA }\end{array}$ \\
\hline $11 / 16 / 2011$ & 423 & Smooth & 0.548 & $\begin{array}{l}\text { Steady state data collected at experiment Mach } 1.30 \& \\
1.50 \text { as well as } 0 \text { degrees experiment AOA }\end{array}$ \\
\hline $12 / 14 / 2011$ & 424 & Smooth & 0.532 & $\begin{array}{l}\text { Additional test points for local flow investigation flown. } \\
\text { Data collected in level accel from experiment Mach } 1.00 \text { - } \\
\text { 1.65. After test point flight was diverted to Palmdale }\end{array}$ \\
\hline $12 / 14 / 2011$ & 425 & Smooth & 0.532 & Return Ferry Flight to Edwards \\
\hline $1 / 5 / 2012$ & 426 & Smooth & 0.532 & Repeat of Flight 422 experiment Mach 1.50 test point \\
\hline
\end{tabular}

\section{Results and Comparisons}

Data were examined for the flights at the conditions of interest (Mach 1.30, 1.50, and 0 deg local AOA) and sections where the conditions were held best were identified. Comparisons of the aircraft pressure altitude, local (experiment) Mach number, and local (experiment) AOA for the identified sections of the data for the Mach 1.50, Ath/Ain $=0.532$ test condition for both the smooth and channeled center-body configurations are shown in Fig. 6 . Similar plots for all test conditions can be found in Ref. 4. In the data legend labels, C denotes channeled center-body data, and $\mathrm{S}$ denotes smooth center-body data. Altitude was maintained within $700 \mathrm{ft}$ for all test conditions, and in the majority of cases was held within +/- 300-400 ft. Mach number was held within +/- 0.02 Mach in all cases. In the 0 deg AOA cases, AOA was held to within $+/-0.5 \mathrm{deg}$. 

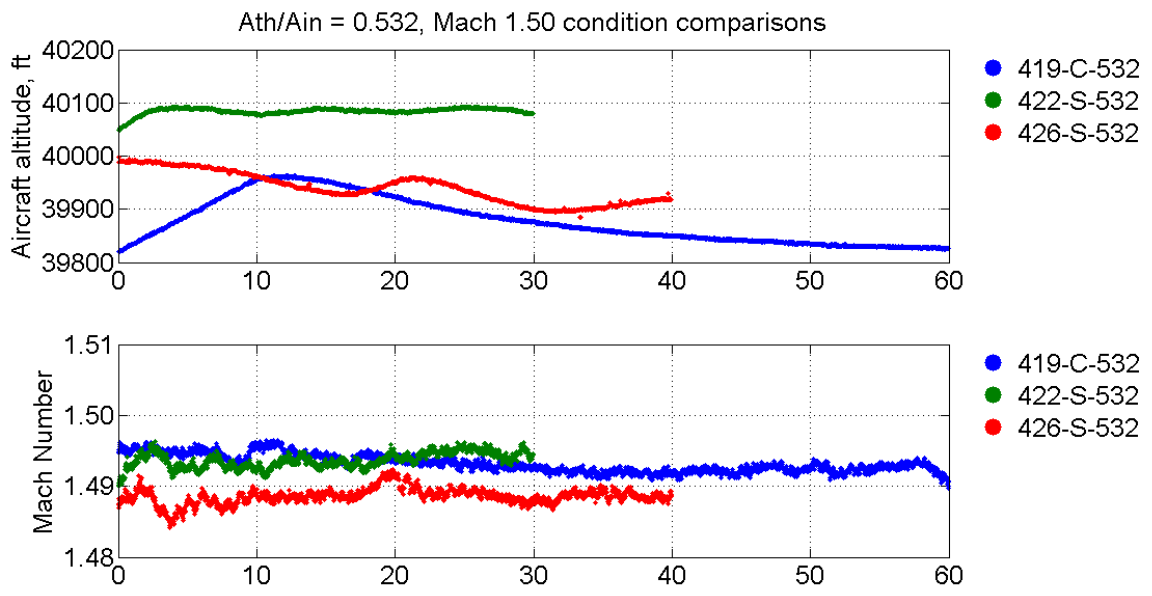

- 419-C-532

- 422-S-532

- $426-5-532$

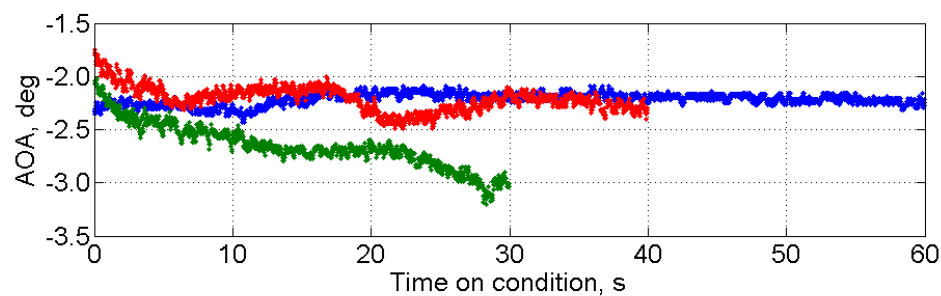

- 419-C-532

- 422-S-532

- $426-5-532$

Figure 6. The Mach 1.5, Ath/Ain = 0.532 test window aircraft altitude, experiment Mach number, and experiment angle of attack comparison across flights.

Note that the figure legend is of the form $X X X-Y$-ZZZ, where $X X X$ is the flight number, $Y$ is either $C$ for the channeled center-body or $S$ for the smooth center-body, and ZZZ is the Ath/Ain for the test point.

Table 3 shows the averaged conditions for all steady test points flown along with the flight and configuration of the inlet. In all, 24 test points were examined. Contour plots of local flow conditions (Mach number, AOA (downwash), sideslip (sidewash), and total pressure variation) from the RAGE local flow investigation flights corresponding to the Mach 1.50, Ath/Ain = 0.532 condition, channeled center-body configuration in table 3 are contained in Fig. 7. (Note that the Mach 1.50 test condition for the inlet corresponds to an aircraft Mach number of 1.66 and for this particular configuration was held at an experiment Mach number of 1.49.) Similar contour plots for all test conditions with corresponding RAGE data are contained in Ref. 4. 
Table 3. Conditions averaged across steady state hold test window.

\begin{tabular}{|c|c|c|c|c|c|c|c|c|}
\hline \multirow[b]{2}{*}{ Flight } & \multirow[b]{2}{*}{ Inlet } & \multirow[b]{2}{*}{ Ath/Ain } & \multicolumn{6}{|c|}{ Averaged Conditions Over Test Point } \\
\hline & & & Aircraft Mach & $\begin{array}{c}\text { Experiment } \\
\text { Mach }\end{array}$ & AOA $[\mathrm{deg}]$ & Sideslip [deg] & $\begin{array}{c}\text { Mass Flow } \\
\text { [lbm/s] }\end{array}$ & $\begin{array}{c}\text { Experiment } \\
\text { Static Pressure } \\
\text { [psia] }\end{array}$ \\
\hline 416 & Channeled & 0.529 & 1.68 & 1.49 & -2.62 & 0.36 & 7.30 & 3.53 \\
\hline 416 & Channeled & 0.529 & 1.25 & 1.30 & 2.19 & 0.78 & 4.63 & 2.60 \\
\hline 416 & Channeled & 0.529 & 1.26 & 1.31 & 1.94 & 0.71 & 4.59 & 2.55 \\
\hline 419 & Channeled & 0.532 & 1.66 & 1.49 & -2.22 & 0.29 & 7.19 & 3.39 \\
\hline 419 & Channeled & 0.532 & 1.24 & 1.29 & 2.48 & 0.63 & 4.64 & 2.58 \\
\hline 419 & Channeled & 0.532 & 1.25 & 1.30 & 2.10 & 0.46 & 4.67 & 2.57 \\
\hline 419 & Channeled & 0.532 & 1.44 & 1.41 & 0.02 & 0.25 & 5.74 & 2.86 \\
\hline 420 & Channeled & 0.548 & 1.69 & 1.50 & -2.43 & 0.31 & 7.51 & 3.50 \\
\hline 420 & Channeled & 0.548 & 1.24 & 1.29 & 2.68 & 0.57 & 4.71 & 2.58 \\
\hline 420 & Channeled & 0.548 & 1.24 & 1.29 & 2.46 & 0.35 & 4.65 & 2.54 \\
\hline 420 & Channeled & 0.548 & 1.46 & 1.42 & 0.18 & 0.27 & 5.92 & 2.85 \\
\hline 421 & Smooth & 0.529 & 1.72 & 1.50 & -3.25 & 0.36 & 7.58 & 3.62 \\
\hline 421 & Smooth & 0.529 & 1.26 & 1.30 & 2.02 & 0.75 & 4.75 & 2.58 \\
\hline 421 & Smooth & 0.529 & 1.25 & 1.30 & 1.95 & 0.56 & 4.69 & 2.56 \\
\hline 421 & Smooth & 0.529 & 1.42 & 1.40 & 0.00 & 0.12 & 5.72 & 2.84 \\
\hline 422 & Smooth & 0.532 & 1.69 & 1.49 & -2.65 & 0.37 & 7.50 & 3.48 \\
\hline 422 & Smooth & 0.532 & 1.26 & 1.30 & 1.86 & 0.84 & 4.93 & 2.60 \\
\hline 422 & Smooth & 0.532 & 1.25 & 1.30 & 1.86 & 0.50 & 4.83 & 2.58 \\
\hline 422 & Smooth & 0.532 & 1.43 & 1.40 & -0.01 & 0.08 & 5.87 & 2.84 \\
\hline 423 & Smooth & 0.548 & 1.68 & 1.49 & -2.04 & 0.38 & 7.66 & 3.45 \\
\hline 423 & Smooth & 0.548 & 1.25 & 1.29 & 2.20 & 0.59 & 4.95 & 2.58 \\
\hline 423 & Smooth & 0.548 & 1.26 & 1.30 & 1.90 & 0.41 & 4.97 & 2.57 \\
\hline 423 & Smooth & 0.548 & 1.48 & 1.43 & 0.01 & 0.07 & 6.33 & 2.92 \\
\hline 426 & Smooth & 0.532 & 1.66 & 1.49 & -2.21 & 0.39 & 7.32 & 3.39 \\
\hline
\end{tabular}

American Institute of Aeronautics and Astronautics 
Aircraft Mach 1.66 Experiment Mach Contour

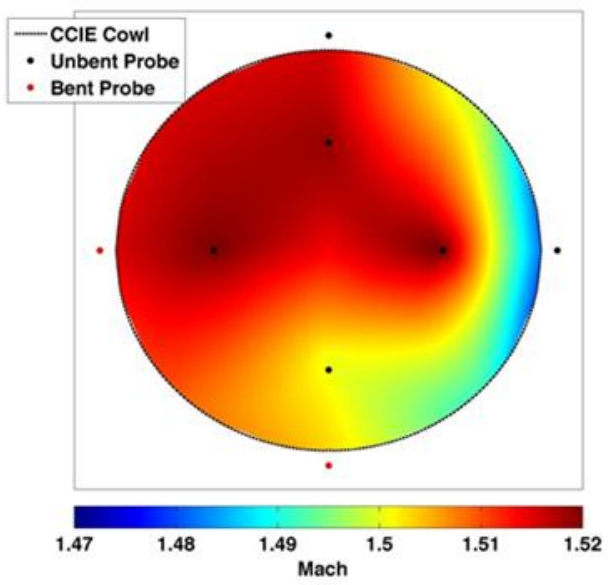

Aircraft Mach 1.66 Experiment Sideslip Contour

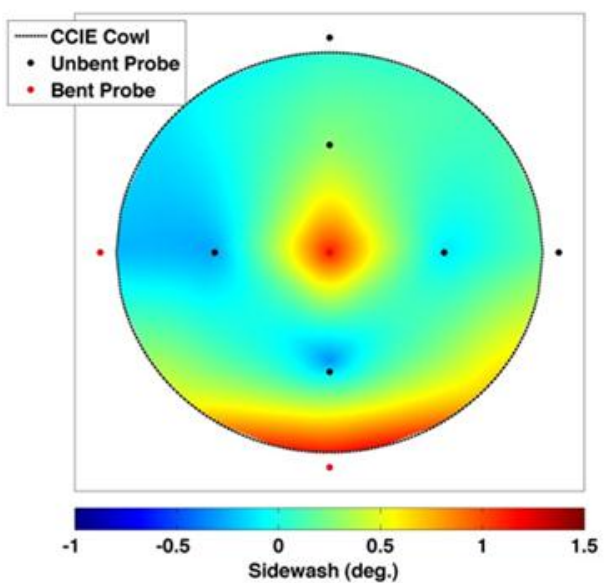

Aircraft Mach 1.66 Experiment AOA Contour

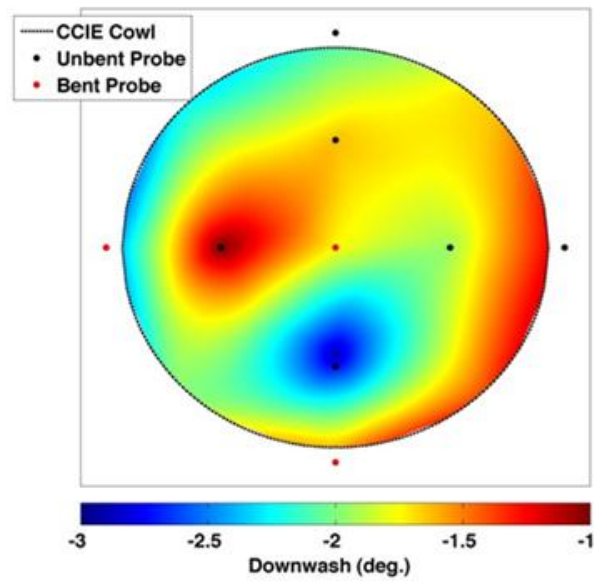

Aircraft Mach 1.66 Experiment Total Pressure Contour

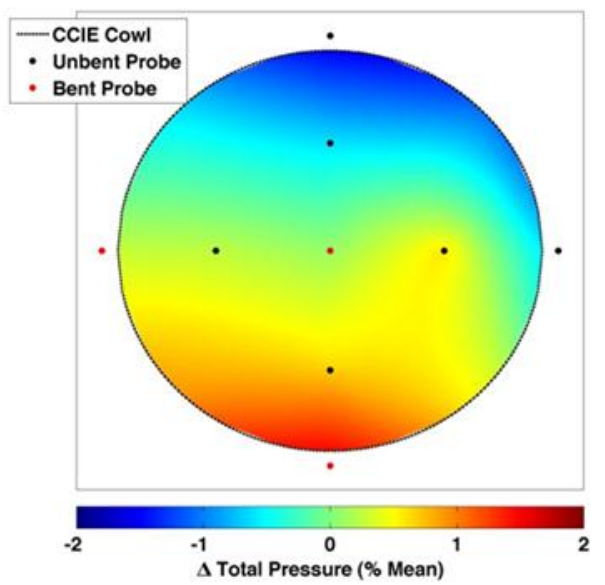

Figure 7. The flow condition contours created by interpolating the Rake Airflow Gage Experiment flight measurements at the inlet aerodynamic interface plane.

The RAGE flow-field rake was calibrated over a limited Mach number range (1.46-1.61). As a result, local flow information at the test inlet aerodynamic interface plane from the RAGE flights is not available for all of the inlet test conditions shown in table 3. The conditions at which RAGE data are available are at free stream (airplane) Mach numbers of $1.48,1.66,1.68,1.69$, and 1.72 . Note that the center, bottom, and starboard probes of the rake were unintentionally bent by very small amounts during pre-flight leak checks of the pressure tubing. The probes were straightened as best as possible; however, it was not possible to quantify the angular difference between the original and straightened configurations. As a result, the flow property calculations from these three probes have an additional unquantifiable error associated with them. This additional error is thought to primarily affect the measured flow angles, as the computed Mach number has a weak dependence on flow angle for angles less than 5 deg. In Fig. 7, the three reworked probes are shown as red circles while the remaining six probes are shown as black circles. The shape of the test inlet cowl is shown as a dashed black line.

Mass capture fraction, pressure recovery, and distortion were calculated using the inlet data collected. Distortion was calculated utilizing the data from the total pressure rakes and Eq. (1). ${ }^{5}$ 


$$
\text { Distortion }=\frac{P_{M a x}-P_{\text {Min }}}{P_{A v g}}
$$

where: $P_{M a x}$ is the maximum measured pressure from all three rakes

$P_{\text {Min }}$ is the minimum measured pressure from all three rakes

$P_{A v g}$ is the average of the measured pressures from all three rakes

Note that the rakes only cover 1/6th of the inlet cross section and thus the calculated distortion only applies to this section of the inlet. These data were then averaged over each test condition. The condition-averaged distortion data are shown in Fig. 8. In the data legend labels, $\mathrm{C}$ denotes channeled center-body data, $\mathrm{S}$ denotes smooth center-body data, and $\mathrm{R}$ denotes the repeat data for the $1.30 \mathrm{Mach}$ number test points. Error bars for uncertainty were generated using the Mach 1.30 data sets. The Mach 1.30 data were repeated on each flight with the exception of flight 426. The two Mach 1.30 data sets for each flight were combined and a standard deviation was calculated of that combined data set. This method was intended to provide error bars that would capture not only the measurement and repeatability error, but also the dynamic content error. This results in an error band significantly in excess of the measurement uncertainty alone. A standard deviation of the flight 426 data for the test window was calculated to be used for uncertainty in that case, as there were no repeated test windows. Figure 8 shows all of the averaged distortions plotted as a function of averaged experiment Mach number. It is important to point out that from these plots that the channeled center-body distortion data are not always higher than the smooth center-body data. The Mach 1.30 condition tends to indicate that the smooth center-body provides less distortion, however, the 0 deg AOA data for the Ath/Ain $=0.532$ nozzle as well as the Mach 1.50 data for the Ath/Ain $=0.548$ nozzle indicate no discernible difference in distortion between the channeled and smooth center-body configurations with uncertainty taken into account. The majority of the distortion data comparisons between the channeled and the smooth centerbody for the same condition (Mach number and Ath/Ain in common) fell within 1 percent with the maximum difference at 1.74 percent.

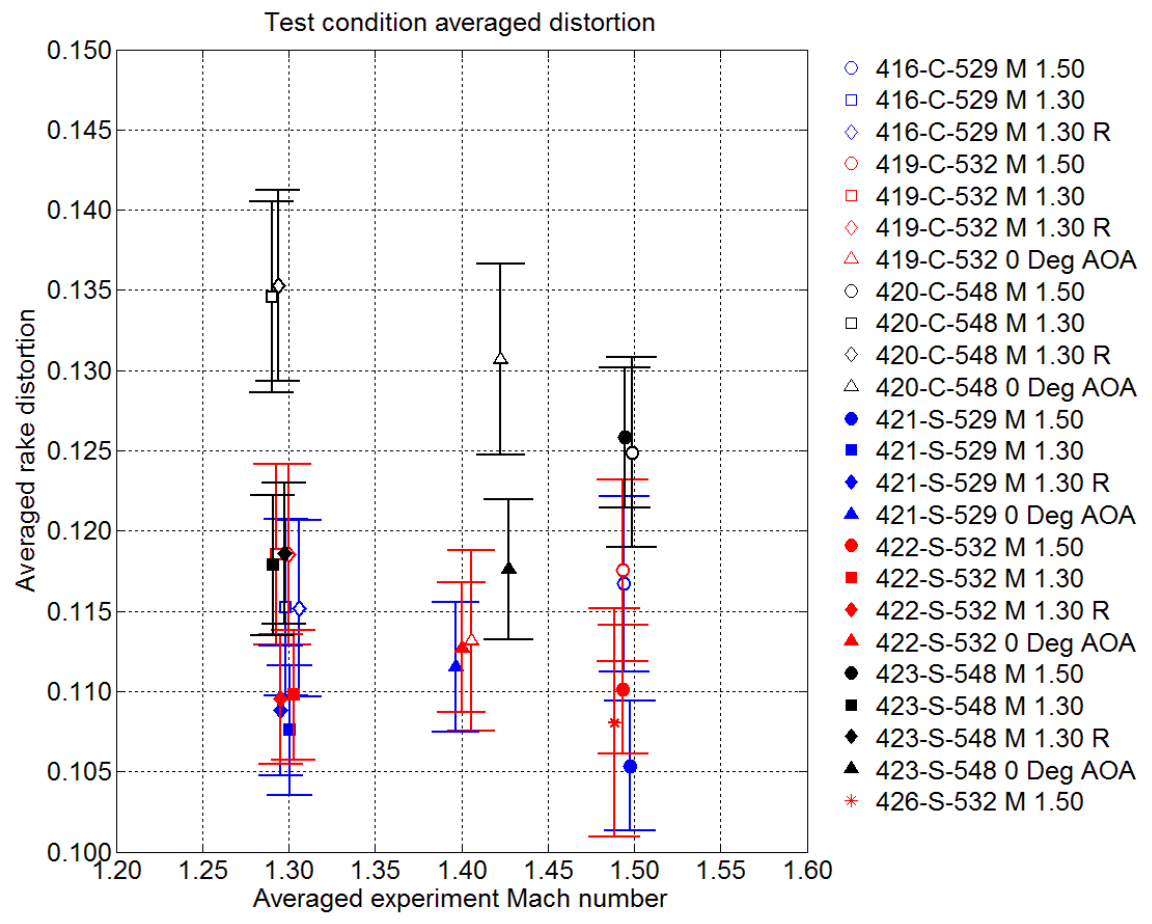

Figure 8. The test condition averaged distortion for all test points.

Note that the figure legend is of the form $X X X-Y-Z Z Z$, where $X X X$ is the flight number, $Y$ is either $C$ for the channeled center-body or $S$ for the smooth center-body, and ZZZ is the Ath/Ain for the test point. 
Filled contour plots of the rake total pressures were generated to illustrate both the dynamic content in the distortion as well as the shapes and locations of the high-pressure regions in the area where data were collected. Figures 9 and 10 present the total pressure contours for the first 9 frames of data taken for the Ath/Ain $=0.532$, Mach 1.50 test condition for both the channeled and smooth center-body configurations respectively. Figures containing the total pressure contours for approximately $1 \mathrm{~s}$ of data collected for all of the test conditions are included Ref. 4. Each frame shown in the figures contains data describing the experiment and aircraft conditions as well as a frame time to orient the reader. The channeled center-body data (Fig. 9) show two high-pressure regions roughly corresponding to the edge of the channels. The size and magnitude of the high-pressure region fluctuates, but maintains roughly the same general shape. The smooth center-body data (Fig. 10) show more uniform pressure bands with a fluctuating and moving high-pressure region. Interestingly, there is some circumferential nonuniformity visible in a large portion of the total pressure contours for the smooth center-body data.
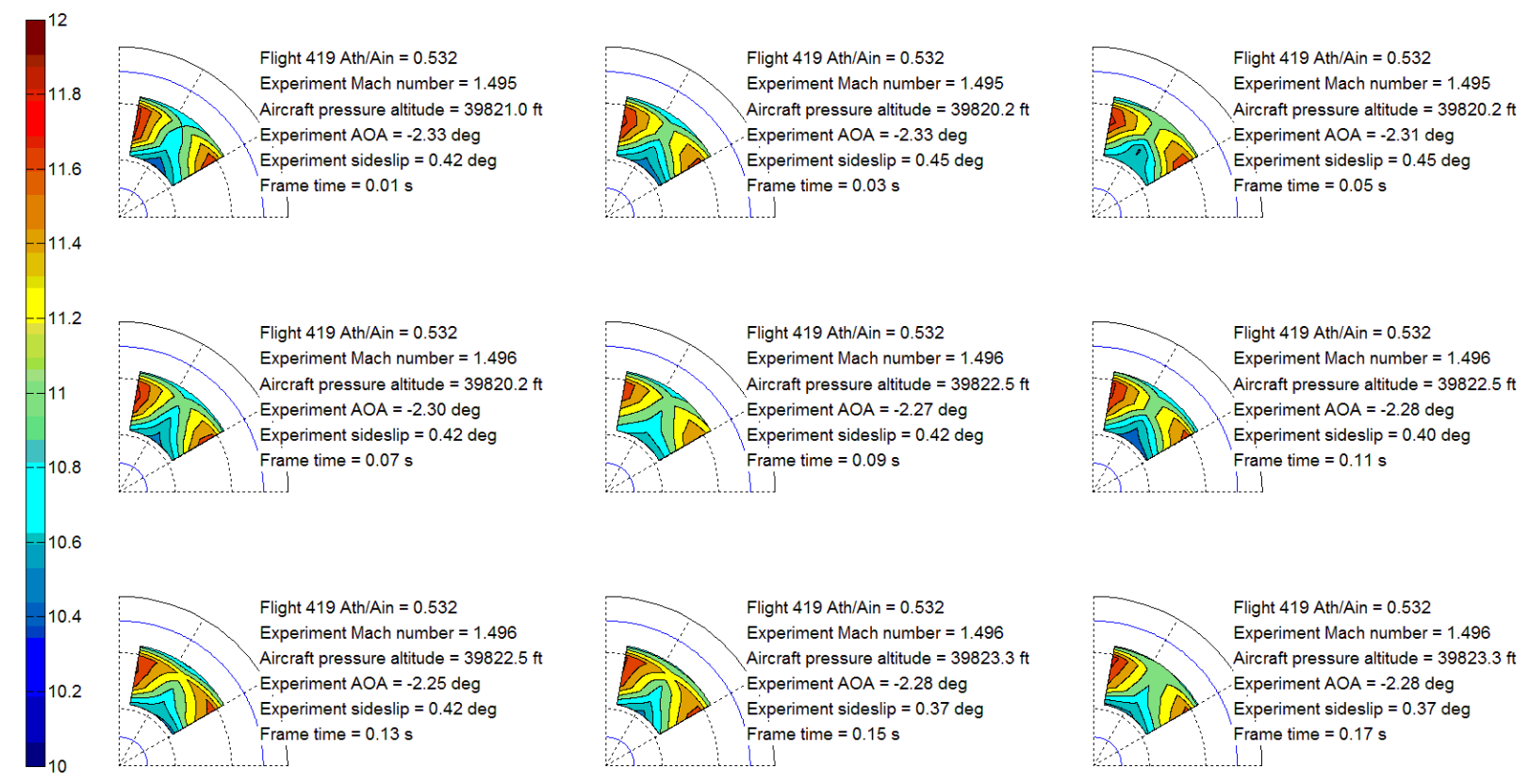

Figure 9. The total pressure contours, psia, progressing in time for flight 419 , channeled center-body, Ath/Ain = 0.532, Mach 1.50 test condition. 

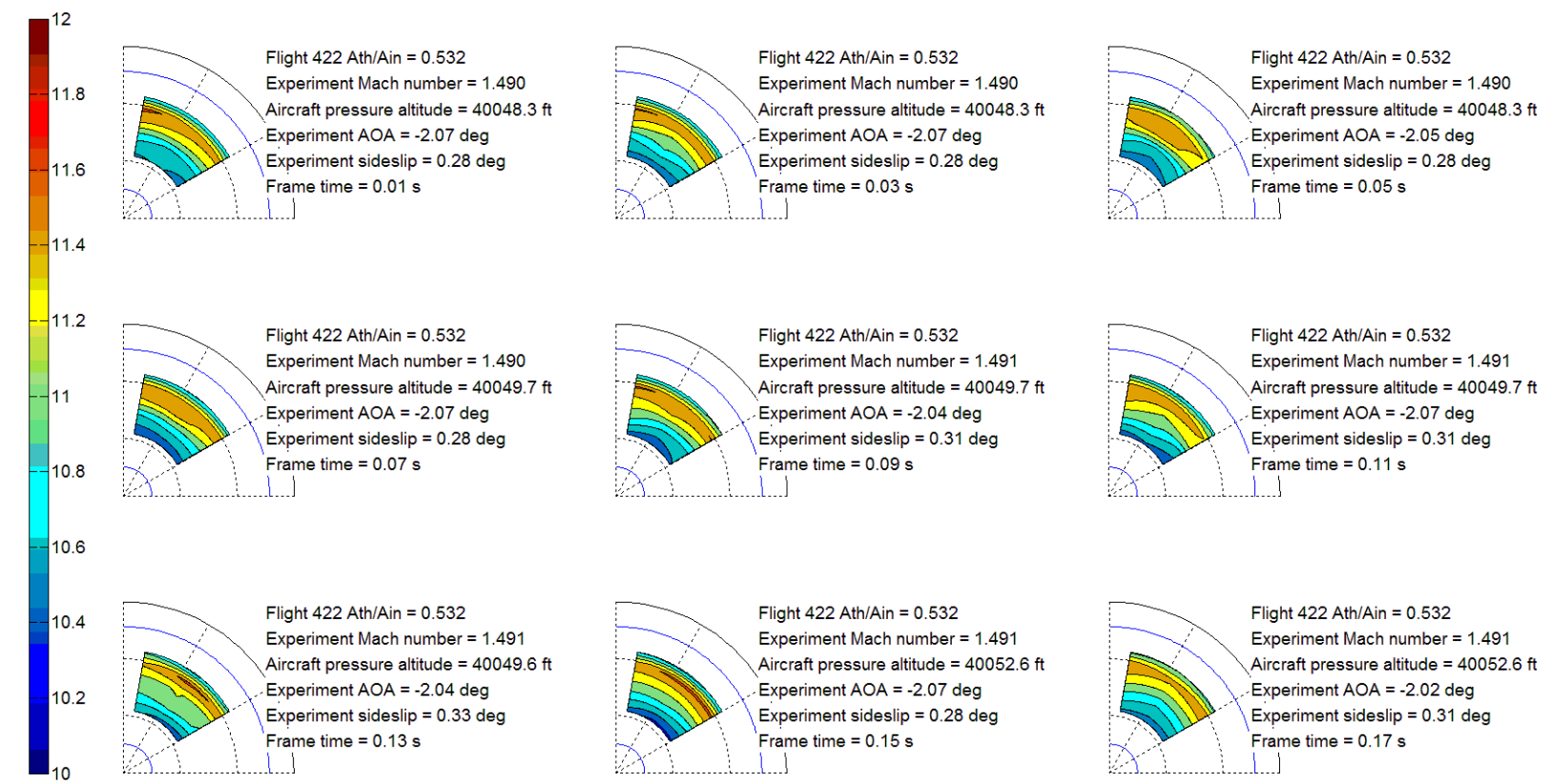

11.2
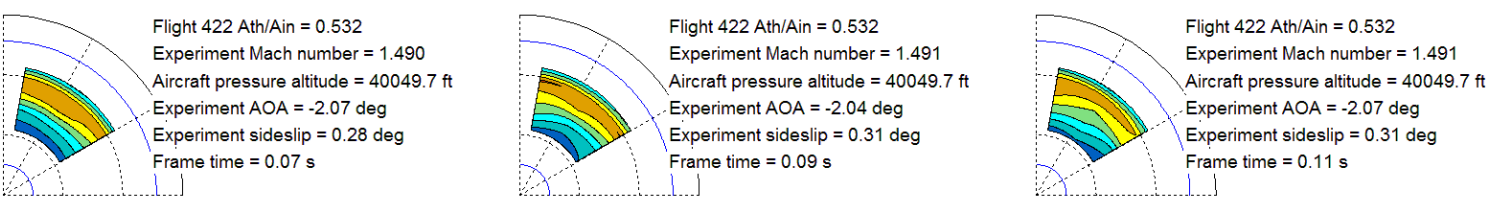

Frame time $=0.07 \mathrm{~s}$

Fram

(1)
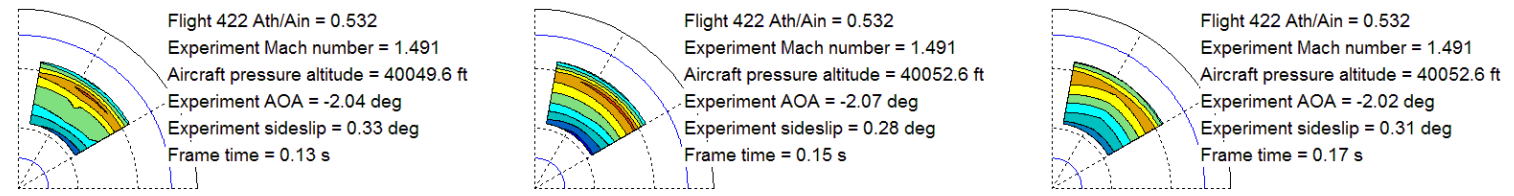

Figure 10. The total pressure contours, psia, progressing in time for flight 422, smooth center-body, Ath/Ain $=0.532$, Mach 1.50 test condition.

Pressure recovery was calculated by dividing the average of the total pressure rake readings by the experiment local total pressure computed from the conical probe. The calculated pressure recovery was then averaged for the various test conditions. Error bars for uncertainty were once again generated by calculating the standard deviation of all of both Mach 1.30 data sets for each flight as well as the flight 426 test condition. Figure 11 shows the condition averaged pressure recovery plotted versus the averaged experiment Mach number. In the majority of the cases the pressure recovery is higher for the smooth center-body configuration. The 1.50 Mach number condition, however, shows a much smaller difference in pressure recovery in the majority of the cases and values within the overlap of the uncertainties for the Ath/Ain $=0.529$ nozzle case. The maximum difference in pressure recovery was 3.54 percent. 


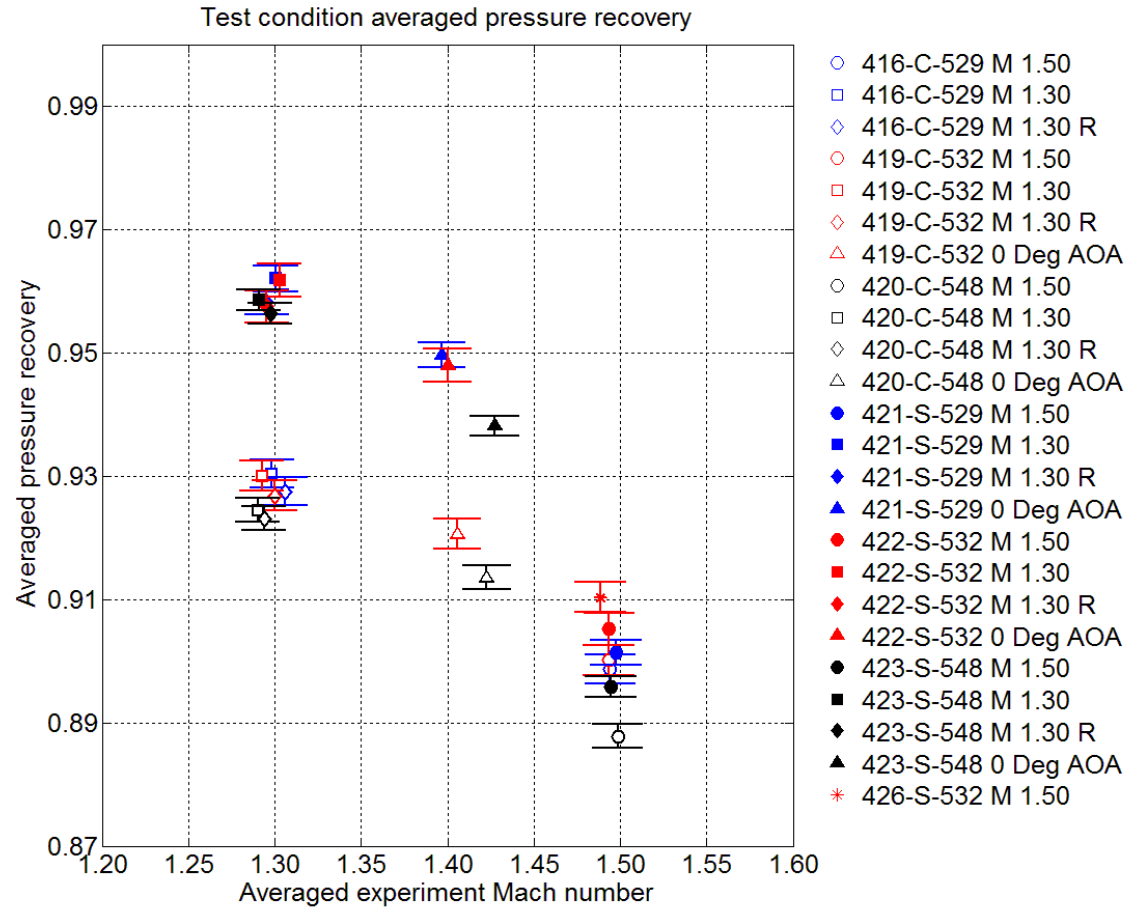

Figure 11. The test condition averaged pressure recovery versus Mach number for all test points. Note that the figure legend is of the form $X X X-Y-Z Z Z$, where $X X X$ is the flight number, $Y$ is either $C$ for the channeled center-body or $S$ for the smooth center-body, and ZZZ is the Ath/Ain for the test point.

Mass capture fraction was calculated using Eq. (2). Note that sonic flow at the nozzle throat is required to simplify the inlet mass flow equation to what is shown.

$$
\begin{gathered}
\text { Mass Capture }=\frac{\dot{m}_{\text {Inlet }}}{\dot{m}_{\text {Max }}} \\
\text { where: } \dot{m}_{\text {Inlet }}=\frac{P_{\text {Noz }} A_{\text {th }}}{\sqrt{T_{0_{\text {Aircraft }}}}}\left(1+\frac{\gamma-1}{2}\right)^{\frac{1}{2}} \\
\text { and: } \dot{m}_{M a x}=P_{0_{\text {Inlet }}} \sqrt{\frac{\gamma}{R T_{0_{\text {Aircraft }}}}} A_{\text {in }} M_{\text {Inlet }}\left(1+\frac{\gamma-1}{2} M_{\text {Inlet }}^{2}\right)^{\frac{-\gamma+1}{2(\gamma-1)}} \\
\text { where: } P_{\text {Noz }} \text { is the average of the measured nozzle static pressures } \\
A_{\text {th }} \text { is the nozzle throat area } \\
\gamma \text { is the ratio of specific heats } \\
T_{0_{\text {Aircraft }} \text { is the total temperature of the airflow ahead of the aircraft }} \text { is the total pressure of the airflow ahead of the inlet } \\
P_{0_{\text {Inlet }}} \text { is the ideal gas constant } \\
A_{\text {in }} \text { is the inlet capture area } \\
M_{\text {Inlet }} \text { is the Mach number of the airflow ahead of the inlet }
\end{gathered}
$$

Figure 12 shows the averaged pressure recovery plotted versus the averaged mass capture fraction. These data show that the mass capture fractions for the given conditions differ between the smooth and channeled center-bodies (with a maximum difference of 2.24 percent). Note that there are a couple of ways comparisons can be made in the plot. Tracing data along a particular flight (for instance, the open blue symbols corresponding to flight 416) will give a curve of pressure recovery as a function of mass capture changes for the channeled center-body configuration with 
Ath/Ain $=0.529$. This, however, is created by varying Mach number and, as such, includes an inherent AOA variation as well. A better comparison can be made by comparing the same inlet configuration at the same Mach number across differing Ath/Ain values. The open square symbols, for example, from blue to red to black, would correspond to the channeled center-body configuration at Mach 1.50, which would provide a comparison of pressure recovery for a single inlet configuration, for a single Mach number (and single corresponding AOA) with varying mass capture fraction.

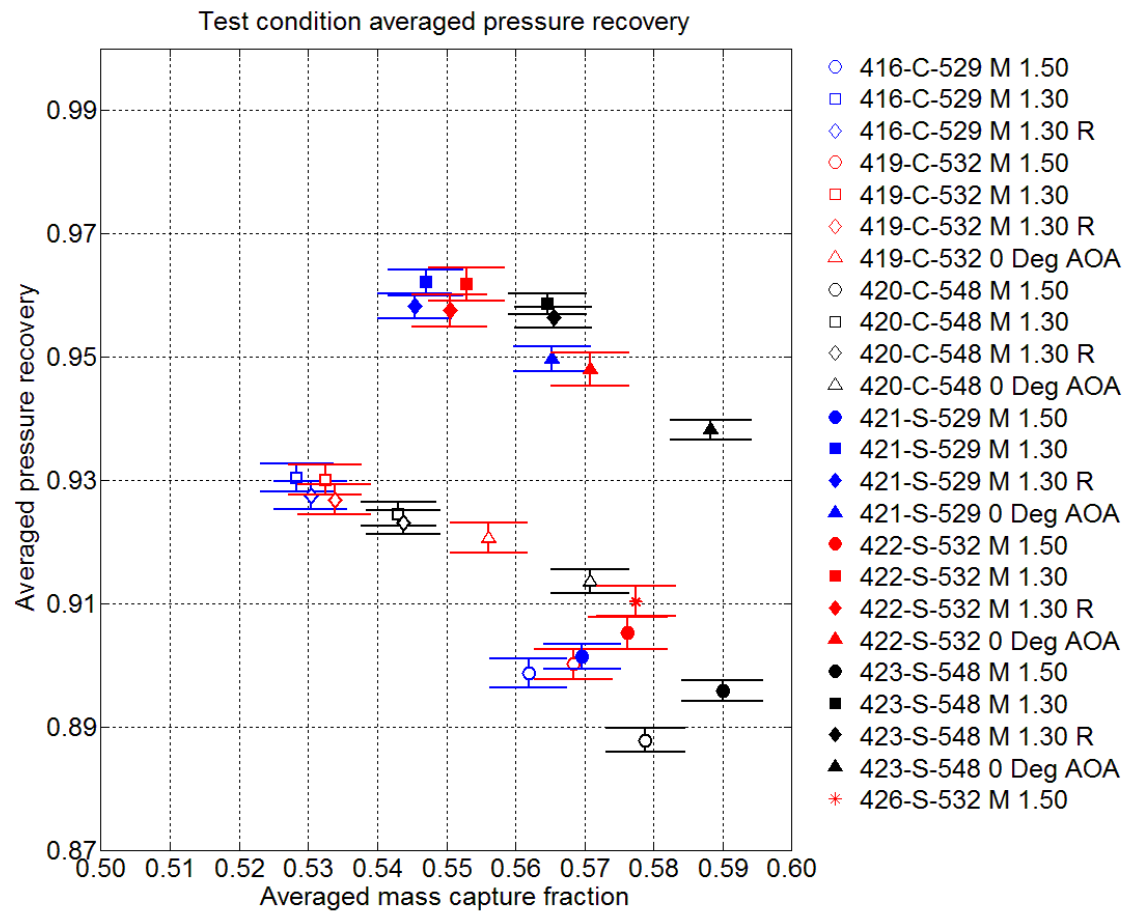

Figure 12. The test condition averaged pressure recovery versus mass capture for all test points Note that the figure legend is of the form $X X X-Y-Z Z Z$, where $X X X$ is the flight number, $Y$ is either $C$ for the channeled center-body or S for the smooth center-body, and ZZZ is the Ath/Ain for the test point.

Table 4 contains the condition time averaged mass capture fraction, pressure recovery, and distortion values for all of the steady state test points. These data are provided in tabular form in addition to the plots to allow for further comparison beyond what has previously been shown. The data in table 4 correspond with the flow condition data previously shown in table 3 . 
Table 4. Condition time averaged mass capture, pressure recovery, and distortion.

\begin{tabular}{|c|c|c|c|c|c|c|c|c|c|}
\hline \multirow[b]{2}{*}{ Flight } & \multirow[b]{2}{*}{ Inlet } & \multirow[b]{2}{*}{ Ath/Ain } & \multicolumn{7}{|c|}{ Averaged Conditions Over Test Point } \\
\hline & & & $\begin{array}{l}\text { Experiment } \\
\text { Mach }\end{array}$ & $\begin{array}{c}\text { Mass Capture } \\
\text { Fraction }\end{array}$ & $\begin{array}{c}\text { Mass Capture } \\
\text { Fraction } \\
\text { Uncertainty } \\
\end{array}$ & $\begin{array}{l}\text { Pressure } \\
\text { Recovery }\end{array}$ & $\begin{array}{c}\text { Pressure } \\
\text { Recovery } \\
\text { Uncertainty }\end{array}$ & Distortion & $\begin{array}{r}\text { Distortion } \\
\text { Uncertainty }\end{array}$ \\
\hline 416 & Channeled & 0.529 & 1.49 & 0.562 & 0.0140 & 0.899 & 0.0023 & 0.117 & 0.0055 \\
\hline 416 & Channeled & 0.529 & 1.30 & 0.528 & 0.0140 & 0.930 & 0.0023 & 0.115 & 0.0055 \\
\hline 416 & Channeled & 0.529 & 1.31 & 0.530 & 0.0140 & 0.928 & 0.0023 & 0.115 & 0.0055 \\
\hline 419 & Channeled & 0.532 & 1.49 & 0.568 & 0.0012 & 0.900 & 0.0024 & 0.118 & 0.0056 \\
\hline 419 & Channeled & 0.532 & 1.29 & 0.532 & 0.0012 & 0.930 & 0.0024 & 0.119 & 0.0056 \\
\hline 419 & Channeled & 0.532 & 1.30 & 0.534 & 0.0012 & 0.927 & 0.0024 & 0.119 & 0.0056 \\
\hline 419 & Channeled & 0.532 & 1.41 & 0.556 & 0.0012 & 0.921 & 0.0024 & 0.113 & 0.0056 \\
\hline 420 & Channeled & 0.548 & 1.50 & 0.579 & 0.0008 & 0.888 & 0.0019 & 0.125 & 0.0059 \\
\hline 420 & Channeled & 0.548 & 1.29 & 0.543 & 0.0008 & 0.924 & 0.0019 & 0.135 & 0.0059 \\
\hline 420 & Channeled & 0.548 & 1.29 & 0.544 & 0.0008 & 0.923 & 0.0019 & 0.135 & 0.0059 \\
\hline 420 & Channeled & 0.548 & 1.42 & 0.571 & 0.0008 & 0.914 & 0.0019 & 0.131 & 0.0059 \\
\hline 421 & Smooth & 0.529 & 1.50 & 0.570 & 0.0070 & 0.901 & 0.0021 & 0.105 & 0.0040 \\
\hline 421 & Smooth & 0.529 & 1.30 & 0.547 & 0.0070 & 0.962 & 0.0021 & 0.108 & 0.0040 \\
\hline 421 & Smooth & 0.529 & 1.30 & 0.545 & 0.0070 & 0.958 & 0.0021 & 0.109 & 0.0040 \\
\hline 421 & Smooth & 0.529 & 1.40 & 0.565 & 0.0070 & 0.950 & 0.0021 & 0.112 & 0.0040 \\
\hline 422 & Smooth & 0.532 & 1.49 & 0.576 & 0.0018 & 0.905 & 0.0026 & 0.110 & 0.0040 \\
\hline 422 & Smooth & 0.532 & 1.30 & 0.553 & 0.0018 & 0.962 & 0.0026 & 0.110 & 0.0040 \\
\hline 422 & Smooth & 0.532 & 1.30 & 0.550 & 0.0018 & 0.958 & 0.0026 & 0.110 & 0.0040 \\
\hline 422 & Smooth & 0.532 & 1.40 & 0.571 & 0.0018 & 0.948 & 0.0026 & 0.113 & 0.0040 \\
\hline 423 & Smooth & 0.548 & 1.49 & 0.590 & 0.0010 & 0.896 & 0.0017 & 0.126 & 0.0044 \\
\hline 423 & Smooth & 0.548 & 1.29 & 0.565 & 0.0010 & 0.959 & 0.0017 & 0.118 & 0.0044 \\
\hline 423 & Smooth & 0.548 & 1.30 & 0.565 & 0.0010 & 0.956 & 0.0017 & 0.119 & 0.0044 \\
\hline 423 & Smooth & 0.548 & 1.43 & 0.588 & 0.0010 & 0.938 & 0.0017 & 0.118 & 0.0044 \\
\hline 426 & Smooth & 0.532 & 1.49 & 0.577 & 0.0007 & 0.910 & 0.0024 & 0.108 & 0.0071 \\
\hline
\end{tabular}

\section{Test Technique Limitations}

One of the goals of the experiment was to evaluate the test technique capabilities and limitations. The test technique was effective for gathering the data shown, however, there are limitations to the methods used. The most significant of these limitations were control of mass flow rate and variation in experiment AOA. These limitations did not prevent the required data from being gathered; however, they do offer areas for potential capability improvements.

As stated earlier, the mass flow rate through the inlet was set using a fixed-geometry nozzle. The mass flow is determined by the nozzle area and the conditions of the flow entering the inlet. The flow entering the inlet is determined by the altitude, Mach number, and atmospheric variation (weather). While Mach number and altitude can be controlled, variations in mass flow will occur in data taken on varying days based on weather, or, stated differently, deviations from the standard day, which cannot be controlled. On any given day, adjustments to the mass flow can only be accomplished by varying the flight conditions (Mach number or altitude), limiting the experimenter to one mass flow rate for a given flight condition. This results in an increase in the number of flights required to test at multiple mass flow rates (for a given flight condition) as each additional mass flow rate requires a nozzle hardware change and a new flight.

Variation in experiment AOA exists due to the local flow characteristics under the F-15B airplane. This variation in experiment AOA as a function of Mach number means that for a given configuration, purely axial flow ( 0 deg AOA) can only be achieved at one Mach number. This condition can be compensated for by mounting the experiment in such a way as to align it to the local flow at the primary test condition of interest. Ground clearance (the distance between the experiment and the ground in the event of a failed strut or flat tire on takeoff or landing), however, constrains the extent to which this can be done, as is evidenced by the non-zero AOA shown in table 3 for the test points at an experiment Mach number of 1.50. For this experiment configuration, as was described earlier, the maximum angle that the experiment could be inclined was $5 \mathrm{deg}$. This minimized the AOA on the Mach 1.50 condition, which was the primary condition of interest, to the extent possible, but only provided axial flow at the Mach 1.40 condition. Future experiments will have to account for this variation in AOA in the design phase as well, to ensure that the desired AOA can be achieved for the desired test condition. 


\section{Summary and Conclusions}

Data were presented for the tests conducted to show the quality of the test conditions (how well points were held as well as local (experiment) flow uniformity) and the performance of the inlet (mass capture fraction, pressure recovery, and distortion). Data were presented for both the channeled and smooth center-body configurations at Mach numbers of approximately 1.30 and 1.50 for the area ratios between the nozzle throat (Ath) and the inlet capture area (Ain) of Ath/Ain $=0.529,0.532$, and 0.548, as well as data for the 0 deg angle of attack, Ath/Ain $=0.532$ and 0.548 , channeled, and Ath/Ain $=0.529,0.532$, and 0.548 smooth center-body, configurations. Mass capture tended to be higher for the smooth center-body configuration than for the channeled. Distortion was not always higher for the channeled center-body than for the smooth, and in fact was not discernibly different for the Ath/Ain = 0.532, 0 deg angle of attack nor the Ath/Ain = 0.548, Mach 1.50 cases. The distortion of both the channeled and smooth center-body configurations was not constant, and contained some dynamic content within the steady state test conditions flown. Pressure recovery was higher for the smooth center-body inlet than for the channeled, with the exception of the Ath/Ain $=0.529$, Mach 1.50 case, in which the two fell within overlapping uncertainties.

The test techniques utilized were proven capable of obtaining the desired data. Limitations and areas for future improvement in capabilities were identified in the areas of mass flow control and local flow angularity.

\section{References}

${ }^{1}$ Weir, L. J., Sanders, B. W., and Vachon, J.,"A New Design Concept for Supersonic Axisymmetric Inlets," AIAA 2002-3775, 2002.

${ }^{2}$ Bowditch, D. N., "Some Design Considerations for Supersonic Cruise Mixed Compression Inlets," AIAA 731269, 1973.

${ }^{3}$ Frederick, M. A., and Ratnayake, N. A., "Flight Test Results from the Rake Airflow Gage Experiment on the F-15B Airplane," NASA/TM-2011-215977, 2011.

${ }^{4}$ St. John, C. W., and Frederick, M. A., "Flight Test Results of an Axisymmetric Channeled Center-body Supersonic Inlet at Off-Design Conditions," NASA/TM-2013-216535 (to be published).

${ }^{5}$ Seddon, J., and Goldsmith, E. L., Intake Aerodynamics, American Institute of Aeronautics and Astronautics, Inc., New York, 1985, p. 301. 